\title{
Ranking of Academic Programs using Fuzzy Modified Topsis
}

\author{
Rosma Mohd Dom, Haliza Hasan, Ainon Mardhiyah Shahidin ${ }^{*}$ and Nur Ainina Apandi \\ Faculty of Computer and Mathematical Sciences, Universiti Teknologi MARA, 40450 Shah Alam, \\ Selangor Darul Ehsan, Malaysia
}

\begin{abstract}
Academic program ranking is very important for education providers to gauge the competitiveness and robustness of programs offered at their institutions. Identification of the level of competitiveness and robustness of academic programs involve several criteria and is very subjective to human judgements. Thus, a multi-criteria decision method with fuzzy environment is applied to solve the ranking problem. This paper highlights the ranking of 11 academic programs offered at the Faculty of Computer and Mathematical Sciences, Universiti Teknologi MARA (UiTM), Shah Alam based on 7 criteria with 12 decision makers. The methodology consists of 2phases. First, determining the importance weightage of 7 criteria using Fuzzy Analytical Hierarchy Process (FAHP) method. Second, ranking of the 11 academic programs using modified Fuzzy Technique for Order of Preference by Similarity to Ideal Solution (MFTOPSIS) method. The results show, future job demand and percentage of graduate employed six months upon graduation are the two most important criteria to be used in ranking the academic programs. While, program Bachelor of Information Technology (Hons) Intelligent System Engineering, Bachelor of Science (Hons) Actuarial Science, and Bachelor of Computer Science (Hons) Netcentric Computing are found to be the three most competitive and robust programs offered by the faculty.
\end{abstract}

Keywords: Academic Programs, AHP, Fuzzy, Ranking, TOPSIS

\section{INTRODUCTION}

Multi Criteria Decision Making (MCDM) has been applied by many organizations in solving their daily decisionmaking problems as it is able to solve problems with conflicting constraints or criteria. Furthermore, when applied with fuzzy environment, Fuzzy Multi Criteria Decision Making (FMCDM), able to solve more complicated problems which involved elements of subjectivity and vagueness (Harliza et. al., 2013). Performance evaluation is highly subjective since it involves human judgement comprising of multi-criteria and many decision makers, thus best done using multicriteria decision making method in fuzzy environment (Bellman \& Zadeh, 1970; Zadeh, 1965). Similarity measures is a very useful means in comparing fuzzy numbers as it minimizes the loss of information occurs in computational process. Thus, new similarity measures have been introduced for fuzzy sets (Nor Hashimah et. al., 2018) and fuzzy soft sets (Nor Hashimah \& Daud, 2013) for a more consistent result.

The objective of this paper is to propose a multicriteria decision making method with fuzzy environment for the ranking of competitiveness of academic programs offered at higher level education institution.

\section{MATERIALS AND METHODS}

Eleven academic programs from the Faculty of Computer and Mathematical Sciences, UiTM Shah Alam, are ranked based on 7 criteria which include, percentage of Dean's Award recipients, graduates with CGPA $>3.5$, graduates employed six months upon graduation, students' entrance CGPA > 3.0, program popularity, optimum enrolment 
based on allocation of places offered, and future job demand. Data used is collected from respective departments at the faculty for semester September 2017. Inputs from 12 decision makers comprising of top management of the faculty and respective departments were gathered.

The methodology undertaken comprises of two phases. In phase 1, inputs from 12 decision makers are tested to ensure their responses are highly consistent and reliable. Then, the weights of the 7 criteria used to rank the competitiveness of academic programs are determined using fuzzy AHP adapted from (Chang, 1996; Bozbura et. al., 2007) and (Prascevic \& Prascevic, 2016) followed by Phase 2, which is the ranking of academic programs by using Fuzzy Modified TOPSIS adapted from (Vahdani et. al., 2011).

The results of the proposed method are then validated using Fuzzy TOPSIS method.

\section{A. Phase 1: Determine Criteria Weights}

Part1: Checking consistency inputs of decision makers by using Consistency Ratio method (Prascevic \& Prascevic, 2016).

Step 1: Develop a single pairwise comparison matrix for the criteria using the middle elements of the fuzzy number obtained.

Step 2: Calculate the eigenvector $P_{k}^{m}$ and $\lambda_{\max }$ using equations 1 and 2, respectively.

$$
P_{k}^{m}=\frac{\left(\prod_{j=1}^{n} a_{i j}^{m}\right)^{\frac{1}{n}}}{\sum_{i=1}^{n}\left(\prod_{j=1}^{n} a_{i j}^{m}\right)^{\frac{1}{n}}}=\frac{w_{i}}{\sum w_{i}}
$$

where $\mathrm{i}=1,2, . ., \mathrm{n}$ for decision maker, $\mathrm{k}$

$$
\lambda_{\max }^{m}=\left[\sum_{j-1}^{n} P_{k}^{m}\left(a_{i j}^{m}\right)\right]
$$

Step 3: Find Consistency Index (CI).

$$
C I=\frac{\lambda_{\max }^{m}-N}{N-1}
$$

Where $N$ is the number of criteria.

Step 4: Check the Consistency Ratio (CR).

$$
C R=\frac{C I}{R I}
$$

where the value $R I$ depends on the number of criteria.

Part 2: Calculate the weight of each criterion.

Step 1: Aggregate group evaluation on the pairwise comparison matrix for all decision makers.

Step 2: Find the value of fuzzy synthetic extent analysis. The sum of columns and rows are required before calculating the fuzzy synthetic extent analysis.

Step 3: Find the degree of possibility using comparison of fuzzy synthesis analysis.

Step 4: Calculate the weight vector.

Step 5: Normalize the weight vector.

\section{B. Phase 2: Rank the Academic Programs}

Step 1: Define the rating of linguistic terms and construct the decision matrix

Step 2: Determine the normalized matrix.

Step 3: Determine the weighted normalized decision matrix.

Step 4: Defuzzify the weighted normalized decision matrix using centroid method

Step 5: Determine the positive ideal solution $\left(A^{*}\right)$ and negative ideal solution $\left(\boldsymbol{A}^{-}\right)$. First, identify the criteria which benefit attribute or cost attribute. For positive ideal solution, the result of cost attributes is the minimum value among the alternatives and vice versa for benefit attributes. For negative ideal solution, the result of cost attributes is the maximum value among the alternatives and vice versa

(1) for benefit attributes

Step 6: Construct ideal separation matrix $\left(\boldsymbol{D}^{*}\right)$ and antiideal separation matrix $\left(\boldsymbol{D}^{-}\right)$. The ideal separation matrix $\left(\boldsymbol{D}^{*}\right)$ and anti-ideal separation matrix $\left(\boldsymbol{D}^{-}\right)$distinguished among the alternatives in the decision-making process.

Step 7: Calculate collective index (CI). The value of CI is calculated by summation of $\mathfrak{H}_{i}$ and $\boldsymbol{\Im}_{i}$.

Step 8: Rank the alternatives in ascending order. The minimum value of collective index indicated as the best alternative. 


\section{NUMERICAL APPLICATION}

\section{A. Phase1: Determine Criteria Weights}

Part 1: Checking consistency inputs of decision makers by using Consistency Ratio method.

Step 1: Table 1 shows the single pairwise comparison matrix for the criteria using the middle elements of the fuzzy number obtained.

Table 1. Single pairwise comparison matrix for middle element of fuzzy number

\begin{tabular}{|c|c|c|c|c|c|c|c|}
\hline $\mathrm{C}$ & $\mathrm{C} 1$ & $\mathrm{C} 2$ & $\mathrm{C} 3$ & $\mathrm{C} 4$ & $\mathrm{C} 5$ & $\mathrm{C} 6$ & $\mathrm{C} 7$ \\
\hline $\mathrm{C} 1$ & 1 & 1 & 1 & 1 & $2 / 3$ & $2 / 3$ & $2 / 3$ \\
\hline $\mathrm{C} 2$ & 1 & 1 & 1 & 1 & $2 / 3$ & 1 & 1 \\
\hline $\mathrm{C} 3$ & 1 & 1 & 1 & 1 & 1 & 1 & 1 \\
\hline $\mathrm{C} 4$ & 1 & 1 & 1 & 1 & $3 / 2$ & $3 / 2$ & $3 / 2$ \\
\hline $\mathrm{C} 5$ & $3 / 2$ & $3 / 2$ & 1 & $2 / 3$ & 1 & 1 & $2 / 3$ \\
\hline $\mathrm{C} 6$ & $3 / 2$ & 1 & 1 & $2 / 3$ & 1 & 1 & $2 / 3$ \\
\hline $\mathrm{C} 7$ & $3 / 2$ & 1 & 1 & $2 / 3$ & $3 / 2$ & $3 / 2$ & 1 \\
\hline
\end{tabular}

Legend: C - Criteria

Step 2: Calculate the eigenvector and $\lambda_{\max }$.

The calculation to obtain column eigenvector for criterion 1 of middle elements $\left(P_{1}^{m}\right)$ is as follows:

$$
\begin{aligned}
& \begin{aligned}
w_{1}=\left(\prod_{j=1}^{7} a_{1 j}^{m}\right)^{\frac{1}{7}} & =\left(1 \times 1 \times 1 \times 1 \times \frac{2}{3} \times \frac{2}{3} \times \frac{2}{3}\right)^{\frac{1}{7}} \\
& =0.845
\end{aligned} \\
& P_{1}^{m} \\
& =\frac{0.8405}{(0.8405+0.9036+1+1.3554+1+0.9036+1.2247)} \\
& =0.1163
\end{aligned}
$$

The calculations for $w_{i}$ and $P_{i}^{m}$ is continued until criterion 7. The sum of eigenvectors is equal to 1 . Hence, the value $\lambda_{\max }$ is obtained as follows:

$$
\begin{aligned}
\lambda_{\max }^{m} & =\left[\begin{array}{l}
(1 \times 0.1163)+(1 \times 0.125)+(1 \times 0.1384)+(1 \times 0.1875)+ \\
(2 / 3 \times 0.1384)+(2 / 3 \times 0.125)+(2 / 3 \times 0.1694)
\end{array}\right] \\
& +\ldots \ldots . . . \\
& +\left[\begin{array}{l}
(3 / 2 \times 0.1163)+(1 \times 0.125)+(1 \times 0.1384)+(2 / 3 \times 0.1875)+ \\
(3 / 2 \times 0.1384)+(3 / 2 \times 0.125)+(1 \times 0.1694)
\end{array}\right] \\
= & 7.0941
\end{aligned}
$$

Step 3: Find Consistency Index (CI).

$$
C I=\frac{7.0941-7}{7-1}=0.01569
$$

Step 4: Check the Consistency Ratio (CR).

$$
C R=\frac{0.01569}{1.32}=0.01189
$$

Since the value of CR is less than o.1, the evaluation from the decision makers is acceptable

Part 2: Calculate the weight of each criterion.

Step 1: The group comparison matrix is shown in Table 2.

Table 2. Group Comparison Matrix

\begin{tabular}{cccc}
\hline $\mathrm{C}$ & $\mathrm{C} 1$ & $\mathrm{C} 2$ & $\mathrm{C} 3$ \\
\hline $\mathrm{C} 1$ & $(1,1,1)$ & $(1 / 2,7 / 8,4 / 3)$ & $(4 / 7,4 / 5,8 / 7)$ \\
$\mathrm{C} 2$ & $(3 / 4,8 / 7,2)$ & $(1,1,1)$ & $(3 / 4,8 / 7,13 / 4)$ \\
$\mathrm{C} 3$ & $(7 / 8,5 / 4,7 / 4)$ & $(3 / 5,7 / 8,3 / 2)$ & $(1,1,1)$ \\
$\mathrm{C} 4$ & $(1,3 / 2,19 / 9)$ & $(1,3 / 2,19 / 9)$ & $(6 / 5,3 / 2,13 / 6)$ \\
$\mathrm{C} 5$ & $(1,3 / 2,2)$ & $(6 / 7,5 / 4,9 / 5)$ & $(1,5 / 4,2)$ \\
$\mathrm{C} 6$ & $(4 / 5,7 / 6,12 / 7)$ & $(5 / 7,1,13 / 8)$ & $(1,11 / 9,17 / 9)$ \\
$\mathrm{C} 7$ & $(11 / 9,12 / 7,16 / 7)$ & $(1,4 / 3,2)$ & $(6 / 5,3 / 2,13 / 6)$ \\
\hline & & & \\
\hline $\mathrm{C}$ & $\mathrm{C} 4$ & $\mathrm{C} 5$ & $\mathrm{C} 6$ \\
\hline $\mathrm{C} 1$ & $(1 / 2,2 / 3,1)$ & $(1 / 2,2 / 3,1)$ & $(3 / 5,6 / 7,11 / 9)$ \\
$\mathrm{C} 2$ & $(1 / 2,2 / 3,1)$ & $(5 / 9,4 / 5,7 / 6)$ & $(3 / 5,1,7 / 5)$ \\
$\mathrm{C} 3$ & $(1 / 2,2 / 3,1)$ & $(1 / 2,4 / 5,6 / 5)$ & $(1 / 2,4 / 5,6 / 5)$ \\
$\mathrm{C} 4$ & $(1,1,1)$ & $(1,3 / 2,2)$ & $(1,11 / 7,2)$ \\
$\mathrm{C} 5$ & $(1 / 2,2 / 3,1)$ & $(1,1,1)$ & $(4 / 7,1,4 / 3)$ \\
$\mathrm{C} 6$ & $(1 / 2,5 / 8,1)$ & $(3 / 4,1,7 / 4)$ & $(1,1,1)$ \\
$\mathrm{C} 7$ & $(5 / 8,1,8 / 5)$ & $(1,7 / 5,2)$ & $(1,7 / 5,2)$ \\
\hline & & &
\end{tabular}

\begin{tabular}{cc}
\hline $\mathrm{C}$ & $\mathrm{C} 7$ \\
\hline $\mathrm{C} 1$ & $(4 / 9,4 / 7,4 / 5)$ \\
$\mathrm{C} 2$ & $(1 / 2,3 / 4,1)$ \\
$\mathrm{C} 3$ & $(1 / 2,2 / 3,1)$ \\
$\mathrm{C} 4$ & $(5 / 8,1,3 / 2)$ \\
$\mathrm{C} 5$ & $(1 / 2,5 / 7,1)$
\end{tabular}

Step 2: The total of Row Sums and Column sums for criteria is shown in Table 3. 


\begin{tabular}{cc}
\hline \multicolumn{2}{c}{ Table 3. Total of Rows and Columns for criteria } \\
\hline C & Row Sums \\
\hline C1 & $(4.0602,5.4735,7.4636)$ \\
C2 & $(4.6689,6.4606,9.3074)$ \\
C3 & $(4.4336,6.0787,8.6106)$ \\
C4 & $(6.9095,9.6155,13.0185)$ \\
C5 & $(5.4544,7.2640,10.2491)$ \\
C6 & $(5.2237,6.8827,9.9771)$ \\
C7 & $(6.8340,9.2299,13.0167)$ \\
\hline & Column Sums \\
\hline C & $(6.7149,9.2264,12.8852)$ \\
\hline C1 & $(5.6006,7.8490,11.3602)$ \\
C2 & $(6.7029,8.4014,12.0099)$ \\
C3 & $(4.0143,5.2235,7.4699)$ \\
C4 & $(5.2231,7.2746,10.0966)$ \\
C5 & $(5.3059,7.5102,10.2591)$ \\
C6 & $(4.0227,5.5198,7.5621)$ \\
C7 & \\
\hline &
\end{tabular}

Total of Row Sums and Column Sums

$=(37.5843,51.0048,71.6430)$

Thus, synthetic values for criterion 1

$$
\begin{aligned}
S_{C 1} & =(4.0602,5.4735,7.4636) \otimes\left(\frac{1}{71.6430}, \frac{1}{51.0048}, \frac{1}{37.5843}\right) \\
& =(0.0567,0.1073,0.1986)
\end{aligned}
$$

The synthetic values for each criterion are shown in Table 4.

Table 4. The Synthetic values for each criterion

\begin{tabular}{cc}
\hline $\mathrm{C}$ & Synthetic values \\
\hline $\mathrm{C} 1$ & $(0.0567,0.1073,0.1986)$ \\
$\mathrm{C} 2$ & $(0.0652,0.1267,0.2476)$ \\
$\mathrm{C} 3$ & $(0.0619,0.1192,0.2291)$ \\
$\mathrm{C} 4$ & $(0.0964,0.1885,0.3464)$ \\
$\mathrm{C} 5$ & $(0.0761,0.1424,0.2727)$ \\
$\mathrm{C} 6$ & $(0.0729,0.1349,0.2655)$ \\
$\mathrm{C} 7$ & $(0.0954,0.1810,0.3463)$ \\
\hline
\end{tabular}

Step 3: The degree of possibility using comparison of fuzzy synthesis analysis are:

$$
\begin{array}{ll}
V\left(S_{C 1} \geq S_{C 2}\right)=0.8733 & V\left(S_{C 1} \leq S_{C 2}\right)=1 \\
V\left(S_{C 1} \geq S_{C 3}\right)=0.9201 & V\left(S_{C 1} \leq S_{C 3}\right)=1 \\
V\left(S_{C 1} \geq S_{C 4}\right)=0.5571 & V\left(S_{C 1} \leq S_{C 4}\right)=1 \\
V\left(S_{C 1} \geq S_{C 5}\right)=0.7772 & V\left(S_{C 1} \leq S_{C 5}\right)=1
\end{array}
$$

$$
\begin{array}{ll}
V\left(S_{C 1} \geq S_{C 6}\right)=0.8198 & V\left(S_{C 1} \leq S_{C 6}\right)=1 \\
V\left(S_{C 1} \geq S_{C 7}\right)=0.5835 & V\left(S_{C 1} \leq S_{C 7}\right)=1 \\
V\left(S_{C 2} \geq S_{C 3}\right)=1 & V\left(S_{C 2} \leq S_{C 3}\right)=0.9563 \\
V\left(S_{C 2} \geq S_{C 4}\right)=0.7097 & V\left(S_{C 2} \leq S_{C 4}\right)=1 \\
V\left(S_{C 2} \geq S_{C 5}\right)=0.9159 & V\left(S_{C 2} \leq S_{C 5}\right)=1 \\
V\left(S_{C 2} \geq S_{C 6}\right)=0.9548 & V\left(S_{C 2} \leq S_{C 6}\right)=1 \\
V\left(S_{C 2} \geq S_{C 7}\right)=0.7371 & V\left(S_{C 2} \leq S_{C 7}\right)=1 \\
V\left(S_{C 3} \geq S_{C 4}\right)=0.6567 & V\left(S_{C 3} \leq S_{C 4}\right)=1 \\
V\left(S_{C 3} \geq S_{C 5}\right)=0.8681 & V\left(S_{C 3} \leq S_{C 5}\right)=1 \\
V\left(S_{C 3} \geq S_{C 6}\right)=0.9083 & V\left(S_{C 3} \leq S_{C 6}\right)=1 \\
V\left(S_{C 3} \geq S_{C 7}\right)=0.6840 & V\left(S_{C 3} \leq S_{C 7}\right)=1 \\
V\left(S_{C 4} \geq S_{C 5}\right)=1 & V\left(S_{C 4} \leq S_{C 5}\right)=0.7927 \\
V\left(S_{C 4} \geq S_{C 6}\right)=1 & V\left(S_{C 4} \leq S_{C 6}\right)=0.7593 \\
V\left(S_{C 4} \geq S_{C 7}\right)=1 & V\left(S_{C 4} \leq S_{C 7}\right)=0.9706 \\
V\left(S_{C 5} \geq S_{C 6}\right)=1 & V\left(S_{C 5} \leq S_{C 6}\right)=0.9620 \\
V\left(S_{C 5} \geq S_{C 7}\right)=0.8214 & V\left(S_{C 5} \leq S_{C 7}\right)=1 \\
V\left(S_{C 6} \geq S_{C 7}\right)=0.7870 & V\left(S_{C 6} \leq S_{C 7}\right)=1
\end{array}
$$

Step 4: For each pairwise comparison, the minimum of the degree of possibility is found to be:

$$
\begin{aligned}
& \operatorname{MinV}\left(S_{C 1} \geq S_{C i}\right)=0.5571 \\
& \operatorname{MinV}\left(S_{C 2} \geq S_{C i}\right)=0.7097 \\
& \operatorname{MinV}\left(S_{C 3} \geq S_{C i}\right)=0.6567 \\
& \operatorname{MinV}\left(S_{C 4} \geq S_{C i}\right)=1 \\
& \operatorname{MinV}\left(S_{C 5} \geq S_{C i}\right)=0.7927 \\
& \operatorname{MinV}\left(S_{C 6} \geq S_{C i}\right)=0.7593 \\
& \operatorname{MinV}\left(S_{C 7} \geq S_{C i}\right)=0.9706
\end{aligned}
$$

Thus, the weight vector:

$$
W^{\prime}=(0.5571,0.7097,0.6567,1,0.7927,0.7593,0.9706)^{T}
$$

Step 5: The normalized weight vector of each criterion is calculated and presented as:

\section{$W=(0.1023,0.1303,0.1206,0.1836,0.1455,0.1394,0.1782)$ \\ B. Phase 2: Rank Academic Programs}

Step 1: The linguistic terms of rating are defined and shown in tables 5 and 6 . Table 7 shows the Decision Matrix for alternatives. 
Table 5. Linguistic term of rating

\begin{tabular}{|c|c|c|}
\hline Linguistic terms & $\mathrm{C} 2$ & $\mathrm{C}_{3}$ \\
\hline Very Poor (VP) & $(0,0,1)$ & $(0,0,10)$ \\
\hline Poor (P) & $(0.5,1,1.5)$ & $(5,10,15)$ \\
\hline $\begin{array}{l}\text { Medium Poor } \\
\text { (MP) }\end{array}$ & $(2,3.5,5) \quad(1,1.5,2)$ & $(10,15,20)$ \\
\hline Fair $(\mathrm{F})$ & $(1.5,2,3.98)$ & $(15,20,35)$ \\
\hline $\begin{array}{l}\text { Medium Good } \\
(\mathrm{MG})\end{array}$ & $(5,8.98,11) \quad(2,3.98,6)$ & $(20,35,60)$ \\
\hline Good (G) & $(8.98,11,20) \quad(3.5,6,10)$ & $(35,60,80)$ \\
\hline Very Good (VG) & $(11,100,100)(6,100,100)$ & $(60,100,10$ \\
\hline Linguistic terms & $\mathrm{C}_{4}$ & $\mathrm{C}_{5}$ \\
\hline Very Poor (VP) & $(0,0,20)$ & $(0,0,10)$ \\
\hline Poor (P) & $(10,20,40)$ & $(5,10,15)$ \\
\hline Medium Poor (MP) & $(20,35,50)$ & $(10,15,20)$ \\
\hline Fair (F) & $(30,40,60)$ & $(15,20,35)$ \\
\hline Medium Good (MG) & $(40,60,80)$ & $(20,35,60)$ \\
\hline Good (G) & $(74.99,84.99,90)$ & $(35,60,80)$ \\
\hline Very Good (VG) & $(84.99,100,100)$ & $50,100,100)$ \\
\hline Linguistic terms & $\mathrm{C}_{7}(1$ & (million) \\
\hline Very Poor (VP) & $(0,0,10)$ & $, 0,0.05)$ \\
\hline Poor (P) & $(5,10,15)$ & $, 0.05,0.07)$ \\
\hline Medium Poor (MP) & $(10,15,20)$ & $5,0.1,0.3)$ \\
\hline Fair (F) & $(15,20,35)$ & $1,0.3,0.5)$ \\
\hline Medium Good (MG) & $(20,35,60)$ & $3,0.5,1.2)$ \\
\hline Good (G) & $(35,60,80)$ & $7,1.2,1.7)$ \\
\hline Very Good (VG) & $(60,100,100)$ & $2,1.7,2.2)$ \\
\hline
\end{tabular}

Table 6. Raw Historical Data Converted into Linguistic Terms for Rating

\begin{tabular}{cccccccc}
\hline$\underline{P}$ & C1 & C2 & C3 & C4 & C5 & C6 & C7 \\
\hline P1 & MG & G & G & VG & MP & VG & MP \\
P2 & VG & VG & F & VG & F & VG & VG \\
P3 & VG & VG & VG & VG & MP & G & MG \\
P4 & VG & VG & G & VG & MP & VG & MG \\
P5 & VG & VG & VP & MG & P & MG & MP \\
P6 & MG & G & G & VG & F & VG & MG \\
P7 & G & VG & G & VG & MP & G & F \\
P8 & VG & VG & G & VG & P & MG & MP \\
P9 & G & VG & G & VG & MP & MG & MG \\
P10 & G & VG & G & VG & MP & G & MG \\
P11 & F & MG & VP & G & MP & VG & MG \\
\hline
\end{tabular}

Legend: P - Program
Table 7. Fuzzy Decision Matrix for Alternatives

\begin{tabular}{|c|c|c|c|c|}
\hline $\mathrm{P}$ & $\mathrm{C} 1$ & $\mathrm{C} 2$ & C3 & $\mathrm{C}_{4}$ \\
\hline $\mathrm{P} 1$ & $(5,8.98,11)$ & $(3.5,6,10)$ & $(35,60,80)$ & $(74.99,84.99,90$ \\
\hline P2 & $(8.98,11,20)$ & $(6,100,100)$ & $(15,20,35)$ & $(40,60,80)$ \\
\hline $\mathrm{P}_{3}$ & $(11,100,100)$ & $(6,100,100)$ & $(60,100,100)$ & $(74.99,84.99,90$ \\
\hline $\mathrm{P}_{4}$ & $(11,100,100)$ & $(6,100,100)$ & $(35,60,80)$ & $(84.99,100,100)$ \\
\hline $\mathrm{P}_{5}$ & $(8.98,11,20)$ & $(6,100,100)$ & $(0,0,10)$ & $(40,60,80)$ \\
\hline P6 & $(5,8.98,11)$ & $(3.5,6,10)$ & $(35,60,80)$ & $(84.99,100,100)$ \\
\hline P7 & $(8.98,11,20)$ & $(6,100,100)$ & $(35,60,80)$ & $(84.99,100,100)$ \\
\hline P8 & $(11,100,100)$ & $(6,100,100)$ & $(35,60,80)$ & $(74.99,84.99,90$ \\
\hline P9 & $(8.98,11,20)$ & $(6,100,100)$ & $(20,35,60)$ & $(84.99,100,100)$ \\
\hline $\mathrm{P} 1$ & $(8.98,11,20)$ & $(6,100,100)$ & $(35,60,80)$ & $(84.99,100,100)$ \\
\hline 0 & & & & \\
\hline P1 & $(4,5,6)$ & $(2,3.98,6)$ & $(0,0,10)$ & $(40,60,80)$ \\
\hline 1 & & & & \\
\hline $\mathrm{P}$ & C & 5 & C6 & $\mathrm{C}_{7}$ (million) \\
\hline P1 & $(10,1$ & $5,20)$ & $60,100,100)$ & $(0.05,0.1,0.3)$ \\
\hline $\mathrm{P} 2$ & $(15,2$ & $0,35)$ & $(60,100,100)$ & $(1.2,1.7,2.2)$ \\
\hline $\mathrm{P}_{3}$ & $(10,1$ & $5,20)$ & $(35,60,80)$ & $(0.3,0.5,1.2)$ \\
\hline $\mathrm{P}_{4}$ & $(10,1$ & $5,20)$ & $(60,100,100)$ & $(0.3,0.5,1.2)$ \\
\hline $\mathrm{P}_{5}$ & $(5,10$ & ,15) & $(20,35,60)$ & $(0.05,0.1,0.3)$ \\
\hline P6 & $(15,2$ & $0,35)$ & $(35,60,80)$ & $(0.3,0.5,1.2)$ \\
\hline P7 & $(10,1$ & $5,20)$ & $(35,60,80)$ & $(0.1,0.3,0.5)$ \\
\hline P8 & $(5,10$ & ),15) & $(20,35,60)$ & $(0.05,0.1,0.3)$ \\
\hline P9 & $(10,1$ & $5,20)$ & $(20,35,60)$ & $(0.3,0.5,1.2)$ \\
\hline P10 & $(10,1$ & $5,20)$ & $(35,60,80)$ & $(0.3,0.5,1.2)$ \\
\hline P11 & $(10,1$ & $5,20)$ & $(35,60,80)$ & $(0.3,0.5,1.2)$ \\
\hline
\end{tabular}

Step 2: Calculate the normalized fuzzy decision matrix for the alternatives with respect.

Step 3: Construct the weighted normalized decision matrix.

Step 4: Defuzzify the weighted normalized decision matrix using centroid method and the results is shown in Table 8. 
Table 8. Defuzzified weighted normalized decision matrix

\begin{tabular}{ccccc}
\hline$\underline{\mathrm{P}}$ & $\mathrm{C} 1$ & $\mathrm{C} 2$ & $\mathrm{C} 3$ & $\mathrm{C} 4$ \\
\hline P1 & 0.0085 & 0.0085 & 0.0703 & 0.1530 \\
P2 & 0.0136 & 0.0895 & 0.0281 & 0.1102 \\
P3 & 0.0719 & 0.0895 & 0.1045 & 0.1530 \\
P4 & 0.0719 & 0.0895 & 0.0703 & 0.1744 \\
P5 & 0.0136 & 0.0895 & 0.0040 & 0.1102 \\
P6 & 0.0085 & 0.0085 & 0.0703 & 0.1744 \\
P7 & 0.0136 & 0.0895 & 0.0703 & 0.1744 \\
P8 & 0.0719 & 0.0895 & 0.0703 & 0.1530 \\
P9 & 0.0136 & 0.0895 & 0.0462 & 0.1744 \\
P10 & 0.0136 & 0.0895 & 0.0703 & 0.1744 \\
P11 & 0.0051 & 0.0052 & 0.0040 & 0.1102 \\
\hline
\end{tabular}

Step 5: Table 9 shows the result for positive and negative ideal solution for all criteria used to rank the alternatives.

Table 9. Positive ideal solution and negative ideal solution

\begin{tabular}{ccc}
\hline C & $\begin{array}{c}\text { Positive ideal } \\
\text { solution }\left(\boldsymbol{A}^{*}\right)\end{array}$ & $\begin{array}{c}\text { Negative ideal } \\
\text { solution }\left(\boldsymbol{A}^{*}\right)\end{array}$ \\
\hline C1 & 0.0719 & 0.0051 \\
C2 & 0.0895 & 0.0052 \\
C3 & 0.1045 & 0.0040 \\
C4 & 0.1744 & 0.1102 \\
C5 & 0.0970 & 0.0416 \\
C6 & 0.1208 & 0.0534 \\
C7 & 0.1377 & 0.0122 \\
\hline
\end{tabular}

Step 6: Calculate values of ideal separation matrix $\left(\boldsymbol{D}^{*}\right)$ and anti-ideal separation matrix $\left(\boldsymbol{D}^{-}\right)$.

Step 7: Calculate values of CI for the alternatives.

Step 8: The minimum value of collective index indicated as the best alternative. Thus, the ranking order for the eleven academic programs is

$\mathrm{P}_{2}>\mathrm{P}_{4}>\mathrm{P}_{3}>\mathrm{P}_{10}>\mathrm{P}_{7}>\mathrm{P} 8>\mathrm{P}_{6}>\mathrm{P}_{5}>\mathrm{P}_{11}>\mathrm{P}_{9}>\mathrm{P}_{1}$

The ranking process is now complete, and the findings are discussed in the next section.

\section{RESULTS AND DISCUSSIONS}

The findings are divided into two parts accordingly. The first is on the criteria weights found using fuzzy AHP. Table 10 shows the importance weights of criteria found using fuzzy AHP.
Table 10. Importance Weight of criteria found using fuzzy AHP

\begin{tabular}{lc}
\hline Criteria & Weights \\
\hline \% Dean's Awards & 0.1023 \\
\%Graduated CGPA > 3.5 & 0.1303 \\
\% Entrance CGPA > 3.0 & 0.1206 \\
\% Graduate Employability (GE) & 0.1836 \\
\% Program Popularity & 0.1455 \\
\% Optimum Enrolment Achieve & 0.1394 \\
\% Future Job Demand & 0.1782 \\
\hline
\end{tabular}

The 3 most important criteria found to be used for ranking of academic programs are Graduate Employability (GE), Future Job Demand and Program Popularity based on UPU application records. While the two least important criteria are obtaining Dean's Award and Entrance CGPA > 3.o. This finding indicates that the major concern is what happens when students completed their studies, in particular the employability and future job prospects. This is understandable due to high percentage of unemployment currently reported in the country.

The criteria weights shown in Table 13 are the results of responses from 12 chosen decision makers. Consistency of all responses was checked using Consistency Ratio (CR) Index. The values of $\mathrm{CR}$ are all less than o.1, the evaluations given by all decision makers are considered significantly consistent thus acceptable to be used for the subsequent stage of the study.

Next, the ranking of 11 academic programs offered at the Faculty of Computer and Mathematical Sciences, UiTM Shah Alam was found using Fuzzy Modified TOPSIS by incorporating the weights found in the earlier phase. Table 14 shows the ranking of the programs understudied.

The 3 most competitive academic programs found are CS243, CS242 and CS251. The two least competitive programs are CS244 and CS240. It is interesting to note that the Actuarial Science program is equally competitive to the Intelligent System Engineering and Netcentric Computing program. This could be due to the fact that graduates in Actuarial Science and Intelligent System Engineering and Netcentric Computing are highly sought after by the industries in the present era of data analytics and digital engineering.

TOPSIS method is used to validate the method applied in ranking of competitiveness of eleven academic programs in this study. 
The results are as tabulated in Table 11:

Table 11. Ranking Academic Program Assessment at Faculty of Computer and Mathematics Sciences, UiTM using Fuzzy Modified TOPSIS by Vahdani et al. (2011)

\begin{tabular}{|c|c|l|c|c|}
\hline \multicolumn{2}{|c|}{ TOPSIS } & & \multicolumn{2}{c|}{ MODIFIED TOPSIS } \\
\hline$\underline{\text { Program }}$ & $\underline{\text { CC }}$ & & $\underline{\text { Program }}$ & $\underline{\text { CI }}$ \\
\hline CS243 & 0.0978 & & CS243 & 4.0257 \\
\hline CS242 & 0.094 & & CS242 & 4.14 \\
\hline CS241 & 0.0845 & & CS251 & 4.4765 \\
\hline CS251 & 0.0827 & & CS246 & 4.6514 \\
\hline CS246 & 0.0778 & & CS245 & 5.1317 \\
\hline CS249 & 0.076 & & CS249 & 5.2773 \\
\hline CS253 & 0.0755 & & CS253 & 51.4635 \\
\hline CS245 & 0.0737 & & CS241 & 35481.65 \\
\hline CS240 & 0.0639 & & CS230 & 35481.7 \\
\hline CS244 & 0.0512 & & CS244 & 35491.74 \\
\hline CS253 & 0.049 & & CS240 & 39294008 \\
\hline
\end{tabular}

Legend: CC - Closeness Coefficient, CI - Coefficient Index

The finding shows that:

a) CS243 and CS242 are found to be the top two programs by both TOPSIS and Modified TOPSIS methods.

b) TOPSIS had picked CS243, CS242, CS251, CS246 and CS245 to be in the top five while Modified TOPSIS had picked CS243, CS242, CS251, CS246 and CS241 to be in the top five. This indicates an $80 \%$ similarity in academic program ranking by both methods used.

c) Similarly, TOPSIS had picked CS249, SC30, CS240, CS244, CS253 and CS245 to be in the bottom six while Modified TOPSIS had picked CS249, SC30, CS240, CS244, CS253 and CS241 to be in the bottom six. This indicates an $83 \%$ similarity in academic program ranking by both methods used.

In summary, ranking of academic programs by Modified TOPSIS method have been validated and the ranking results are acceptable since it is highly consistent with the ranking results using TOPSIS method.

\section{CONCLUSION}

The findings of the study presented in this paper can help education providers and program owners to gauge their programs' relevancy and competitiveness. By knowing where one stands would enable education providers and program owners to plan and strategize on how to enhance the relevancy and competitiveness of their academic programs. This in return will benefit the students of the respective programs now that their programs will be critically designed to suit current needs.

\section{ACKNOWLEDGEMENT}

The authors would like to thank Universiti Teknologi MARA for the financial assistance. This research is funded by the Academic and Research Assimilation (ARAS) Grants of UiTM. 


\section{REFERENCES}

Bellman, R. E. \& Zadeh, L. A. 1970, Decision Making in a Fuzzy Environment, 17(4), pp. 141-164.

Bozbura, F. T., Beskese, A. \& Kahraman, C. 2007, Prioritization of human capital measurement indicators using fuzzy AHP. Expert Systems with Applications, 32(4), pp. 1100-1112.

Chang, D. Y. 1996, Applications of the extent analysis method on fuzzy AHP. European Journal of Operational Research, 95(3), pp. 649-655.

Harliza, M. H., Daud, M. \& Nor Hashimah, S. 2013, Solving decision making problems using fuzzy numbers with area dominance approach. AIP Conference proceedings of National Symposium on Mathematical Sciences, $18^{\text {th }}$ December 2012, Putrajaya, Wilayah Persekutuan.

Nor Hashimah, S. \& Daud, M. 2013, A set theoretic similarity measure for fuzzy soft sets and its application in group decision making. AIP Conference Proceedings of National Symposium on Mathematical Sciences, 18th December 2012, Putrajaya, Wilayah Persekutuan.

Nor Hashimah, S., Daud, M., Jamilah, M. S. \& Sharifah Aniza, S.A. 2018, Extended FTOPSIS with distance and set theoretic-based similarity measure. Indonesian Journal of Electrical Engineering and Computer Science, 9(2), pp. 387-394.

Prascevic, N. \& Prascevic, Ž. 2016, Application of fuzzy AHP method based on eigenvalues for decision making in construction industry (Vol. 1).

Vahdani, B., Mousavi, S. M. \& Tavakkoli-moghaddam, R. 2011, Group decision making based on novel fuzzy modified TOPSIS method. Applied Mathematical Modelling, 35(9), pp. 4257-4269.

Zadeh, L. A. 1965, Fuzzy sets. University of California, Berkeley, California. 